\title{
Contracampo
}

\section{Por um modo de existência do lúdico ${ }^{1}$}

\section{For a playful mode of existence}

André Lemos

alemos@ufba.br

Programa de Pós-Graduação em Comunicação e Cultura Contemporâneas da Faculdade de Comunicação da Universidade Federal da Bahia - UFBA (Brasil).

${ }^{1}$ Uma versão ampliada deste texto será publicada no prefácio do livro de Luiz Adolfo Andrade, "Jogos digitais, cidade e (trans)mídia: a próxima fase", pela Appris Editora (Curitiba).

\section{PPGCOM}

\section{Ao citar este artigo, utilize a seguinte referência bibliográfica}

LEMOS, André. Por um modo de existência do lúdico.

In: Revista Contracampo, v. 32, n. 2 , ed. abril-julho ano 2015. Niterói: Contracampo, 2015. Págs: 4-17.

\section{DOI: $10.5327 / Z 22382577201500320732$}

Enviado em: 04 de mar. de 2014

Aceito em: 01 de jun. de 2015

\section{Edição 32/2015 Comunicação e Materialidades}

Contracampo

e-ISSN 2238-2577
Niterói (RJ), v. 32, n. 2, abr-jul/2015

www.uff.br/contracampo

A Revista Contracampo é uma revista eletrônica do Programa de PósGraduação em Comunicação da Universidade Federal Fluminense e tem como objetivo contribuir para a reflexão crítica em torno do campo midiático, atuando como espaço de circulação da pesquisa e do pensamento acadêmico. 


\section{Resumo}

O objetivo deste artigo é discutir a teoria ator-rede a partir dos "modos de existência", sugerindo a inclusão de mais um modo para pensar a modernidade. Discute-se uma questão que a leitura do último livro do sociólogo francês Bruno Latour, Enquête sur les modes d'Existence (2012), deixa em aberto: a ausência de um "modo de existência" do lúdico. Parece faltar esta que é uma das importantes dimensões da produção da subjetividade moderna. $\mathrm{O}$ artigo apresenta os modos de existência, propõe mais um modo (lúdico), apontando para a existência de "seres do jogo", e estabelece correlações deste com outros modos, como o da técnica, o da metamorfose e o da ficção. O objetivo é contribuir para a discussão sobre a teoria atorrede, os estudos sobre os games e ao campo da comunicação como um todo.

Palavras-chave: Games; Teoria ator-rede; Modos de existência; comunicação.

\section{Abstract}

The aim of this paper is to discuss actornetwork theory from the "modes of existence" perspective, suggesting the inclusion of one another: "game beings". We discuss an issue that the reading of the last book of the French sociologist Bruno Latour, Enquête sur les modes $d^{\prime}$ Existence (2012), leaves open: the absence of a "playful mode of existence." It seems that this mode is one of the most important dimensions of modern subjectivity. The article presents the concept of the "modes of existence", proposes another one (the "ludic"), pointing to the existence of "game beings", and establishes correlations of this with other modes, such as technique, metamorphosis and fiction. The goal is to contribute to the discussion on actor-network theory, games studies and communication science as a whole.

Keywords: Games; actor-network theory; mode of existence; communication. 


\section{Introdução}

modernidade caracteriza-se por uma forma específica de enquadramento da
atividade lúdica, seja para infantilizá-la, seja para ajustá-la como um negócio (do entretenimento). Acredito que a dimensão lúdica seja uma das chaves para empreender uma antropologia dos modernos, já que o que chamarei aqui de "seres do jogo" nos constituem, nos provocam, "jogam" com a nossa subjetividade e com o nosso corpo por intermédio de artefatos ("brinquedos fetiches"), narrativas e regras específicas. É surpreendente não haver nenhuma referência no Enquête sur les modes d'existence. Une anthropologie des modernes (LATOUR, 2012) sobre esse fenômeno.

Os seres do jogo (assim como os seres da técnica, da metamorfose e da ficção, como veremos) nos constituem de fora para dentro, exigem nossa atenção e mesmo a criação de um "mundo a parte", de um outro "espaço-tempo", de um "círculo mágico", se posso usar aqui essa expressão muito utilizada nas análises do jogo. Proponho um "modo de existência do lúdico" próprio dos seres do jogo. Para isso, preciso explicar os "modos de existência" de acordo com a obra de Bruno Latour, mesmo que não possa, neste espaço, fazê-lo com o aprofundamento que o desafio impõe.

\section{Sobre os modos de existência}

No Enquête, Bruno Latour faz uma antropologia dos modernos, tentando responder positivamente a questão colocada em uma de suas obras mais famosas, Jamais fomos modernos (LATOUR, 1994). Se jamais fomos modernos, o que somos então? Para responder a essa questão, Latour explora os principais modos de existência dos seres que fazem de nós modernos. Ser moderno é tomar posições específicas sobre esses modos de existência, é usar chaves próprias (diferente dos "não modernos") de compreensão e/ou reconhecimento de seres específicos. Essa posição indica a forma como os modernos (ocidentais, brancos, europeus ou por eles diretamente influenciados) agem, pensam e constroem um mundo bem particular, o mundo da modernidade.

Podemos identificar esse mundo moderno como aquele produzido a partir de visões próprias sobre os seres, tais como os da "referência", da "religião", do "direito", da "técnica", 
da "política", do "hábito", entre outros. Muitos analistas, não só Latour, descrevem e analisam a modernidade como o período da história da humanidade no qual emergem e tornam-se hegemônicas a visão científica do mundo; o desmerecimento ou a visão exótica de culturas tradicionais; a compartimentalização da vida social em domínios autônomos com a separação da natureza da cultura, do sujeito do objeto; o descrédito do religioso em prol de uma perspectiva racionalista; a autonomização da técnica e a associação do destino com um destino "tecnológico"; o desmerecimento das dimensões do jogo e outras “despesas improdutivas" em prol de uma economia da acumulação e da eficiência etc.

O desafio do Enquête é entender a maneira de ser dos modernos em uma antropologia comparada. Para Latour, eles confundem diversos modos de existência e propõem um mundo à parte, que obscurece a natureza, os objetos, a técnica, a religião, o direito, a política etc. Sua tese principal é que um modo representa seres que se manifestam por alterações e descontinuidades, devendo sempre passar por outros para existir. A ontologia em questão é esta: um ser não se define por sua substância, essência, mas por sua trajetória em busca da subsistência, passando por hiatos e descontinuidades. A análise de todos os modos se dá tendo como premissa não "l'être-en-tant qu'être", mas “l'être-en-tant qu'autre".

Esta perspectiva de "interdependência" dos seres é muito interessante, já que coloca a obra de Latour em uma dimensão ontológica (e não epistemológica), bem como abre um debate político, ambiental e mesmo religioso, pois tudo se dá nas associações, nas redes, nas mediações (reforçando e ampliando a tese da "teoria ator-rede" — LATOUR, 2005; LEMOS, 2013). As trajetórias pressupõem, necessariamente, mediação, tradução, comunicação, transformando tudo em uma rede de influências. O sentido é uma trajetória desenhada por um modo que, por sua vez, define os antecessores e os sucessores, uma linhagem no curso de uma ação. Ou seja, trajetória, ser e sentido podem, na perspectiva do Enquête, ser entendidos como sinônimos.

Latour aponta então os 15 modos de existência, reunidos em 5 grupos a saber:

1. grupo dos "sem quasi objeto e sem quasi sujeito", composto pelos modos da reprodução (REP), metamorfose (MET), hábito (HAB);

2. grupo dos "quasi objetos", composto pelos modos da técnica (TEC), ficção (FIC), referência (REF);

3. grupo dos "quasi sujeitos", formado pelos modos da política (POL), direito (DRO), religião (REL); 
4. grupo da "ligação entre quasi sujeitos e quasi objetos", com os modos da ligação (ATT), organização (ORG) e moralidade (MOR) e;

5. grupo da "metalinguagem", com os modos da rede (RES), preposição (PRE) e duplo clique (DC).

Todos esses 15 modos (ou 12, a depender do leitor, pois podemos não considerar os três últimos como sendo modos) dependem uns dos outros. No entanto, eles têm condições de felicidade e de infelicidade que lhes são próprios, assim como querem sempre fazer valer as suas condições de felicidade sobre as dos outros. Quando um modo tenta "dominar" o outro, temos erros de categoria por adoção de uma preposição (PRE) inadequada. Quando um modo tenta saltar sem pagar as mediações, tem-se o apagamento das redes (RES) pela ação do duplo clique (DC).

O esforço da Enquête é o de identificar (para evitar) os erros de categoria (ou achar a boa preposição), visualizar suas trajetórias em descontinuidades (as redes que vão sendo criadas) e, por fim, apontar as condições de felicidade ou de infelicidade de cada um desses modos. Este trabalho é feito para que possamos garantir uma certa objetividade e racionalidade da experiência analisada, uma maneira de "falar bem" que não esteja associada a um racionalismo abstrato, mas à uma objetividade que paga o preço das mediações. Por exemplo, não se pode analisar o ritual de dança dos índios para produzir a chuva com a visão científica da chuva. Essa mistura é um desrespeito tanto aos índios como aos cientistas e à chuva, já que esta não se esgota nem em uma visão, nem na outra.

O que é verdadeiro e falso se diz então dentro das particularidades de cada modo. É um problema "locativo" portanto, que consiste em evitar os erros de sentido/direção, que nos levariam a confundir as coisas e tomar um modo por outro. No livro, Latour aponta toda a confusão dos modernos que obscurece os seres da natureza e da técnica, que confunde política com ciência, que idealiza um mundo material e simbólico pretendendo ser materialista e contra o idealismo.

O trabalho do Enquête é o de captar a multiplicidade das associações. Isso implica tradução, mediação, passagem de uma coisa por outra na busca pela subsistência. Temos aqui o primeiro elemento da metalinguagem, a noção de RES. Ela é o que os seres criam nas suas trajetórias. Portanto, não há deslocamento e relação sem o estabelecimento de uma conexão custosa entre diversos agentes e domínios. A qualificação dos tipos de conexão 
é uma tomada de posição sobre o modo. Aqui, aparece a segunda metalinguagem, a PRE. Ela é a chave de interpretação de um modo, a posição de julgamento que vai permitir a comparação entre modos diferentes. A falta de uma preposição adequada é erro de categoria. Não reconhecer a mediação é aniquilar as redes.

Cada modo exige uma PRE específica e a visualização de suas RES. Mas o demônio "jogador", o terceiro elemento da metalinguagem da pesquisa, que Latour chama curiosamente de DC, está sempre presente, perturbando, criando erros de categoria e propondo transcendências sem pagar pelas mediações. Devido à ação desse elemento perturbador (seria um elemento lúdico?), de negação da rede, os modernos não percebem nem o particular de cada modo, nem as suas misturas. O cientista ridiculariza a dança dos índios que, para estes, produz a chuva!

Duplo Clique não quer pagar as mediações, não aceita os pequenos hiatos, age por transcendência, defende a substância dos domínios, negas as redes, dá grandes saltos, simplifica e purifica. Ele "apaga o mundo" ao instituir uma experiência sem mediações. Se existir é continuar uma trajetória através de uma superação de descontinuidades, agindo e sofrendo ação no curso das transformações, DC quer nos convencer do contrário. Há algo de brincalhão e jogador nesse demônio das grandes transcendências.

No curso de uma ação, adotamos um determinado entendimento (a preposição que assumimos em certas ocasiões) de que algo é do domínio do direito, da ciência, da religião, do político, do mundo simbólico, da arte... Às vezes tomamos um modo por outro e os erros de categoria começam a se multiplicar. A Enquête quer explicar esses erros através de uma análise que leva em conta o que há de particular em cada modo e a necessidade de identificar as mediações, já que todos devem passar por outros para existir. A Enquête exige o bom posicionamento (PRE) e o reconhecimento das mediações (RES).

Os modos de existência explicam as relações desempenhadas, sempre em composição com outros elementos (as mediações em rede), e as simplificações do processo de hibridização, pela anulação (purificação) dessas mediações por erros de categoria (é frequente tomar algo religioso por científico, científico por jurídico, jurídico por político e assim por diante). Portanto, entender os modernos deve passar por uma tarefa de explicação das misturas dos modos, dos erros de categoria e dos processos de purificação explorados no Jamais fomos Modernos. Esses processos buscam simplificar e tornar os modos menos dependentes uns dos outros, fechados em categorias estanques. 
Acreditando-se racionais, os modernos parecem perdidos em um emaranhado de modos. Esses seres bizarros vão simplificando, em nome do seu pretenso racionalismo, as experiências. Para Latour, desembaraçar os modos é uma necessidade urgente, já que é preciso aprender a dialogar com os outros (não modernos) para instituir um instrumento diplomático que nos ajude a salvar "Gaia". Se tomamos um modo por outro, não vamos conseguir conversar. Essa é, no fundo, a "missão" da Enquête.

Antes de descrever o que chamarei de "modo de existência do lúdico" (LUD) e os seres do jogo, explico rapidamente os modos que se ligam diretamente a ele: os modos de existência dos "seres da Metamorfose" (MET), dos "seres da ficção" (FIC) e dos "seres da técnica" (TEC).

\section{Seres da metamorfose}

Colocando de forma direta e simples, os MET são os que constituem a nossa subjetividade. O Enquête mostra que devemos desconfiar do que os modernos chamam de "mundo invisível", já que o seu materialismo capta mal a experiência e a reprodução dos existentes. Como não podem negar a sua existência, os modernos expatriam esses seres para um mundo à parte, da mesma forma que isolaram os seres da natureza em um mundo material construído.

No projeto moderno, a solução foi propor a criação de um mundo material (no fundo idealista, como explica Latour, já que é uma "res-extensa-cogitans") e o seu duplo, um mundo simbólico. Se algo existe e não está na natureza acessível pela ciência — ou por uma filosofia da essência que não reconhece nada fora da consciência humana (HARMAN, 2011) — para resolver esse problema espacial os modernos dividiram o mundo e exportaram esses seres para uma outra realidade/espaço, a simbólica(o). No caso dos seres da metamorfose, os modernos os deslocam para dentro do "psiquismo dos sujeitos humanos".

No entanto, é pela rede externa que a produção de interioridade se dá. Se há dúvidas sobre a diferença entre objeto e objetividade, deve-se colocar a mesma questão sobre o sujeito e a subjetividade. Uma análise pela teoria ator-rede pode mostrar a grande aparelhagem constituída para a produção da subjetividade, como uma rede produtora de interioridade: psicotrópicos, drogas alucinógenas, confissões públicas, profissões psicanalíticas, filmes 
de terror, jogos eletrônicos. Latour indica aqui vários elementos que remetem para a dimensão lúdica: filmes, jogos, drogas, por exemplo. A experiência mostra que vivemos sempre "sobre influência" desses "psicotropes".

Mas, para os modernos, não há construção exterior, já que eles sonham possuir um “eu” nativo, autóctone, primordial. Mais ainda, eles vão ridicularizar aqueles que acreditam na produção exterior de subjetividade. Há aqui erros de categoria (PRE) e aniquilação das redes (RES). Não se trata de dizer que não há sujeito, mas que a interioridade é produzida e visível do exterior. Sentimos os seres da metamorfose em nossa experiência diária, pois somos tomados por coisas que nos arrebatam. Elas não são reflexos de um interior já dado, mas movimento de instauração pelos MET que precisam da nossa atenção para existirem. Se não somos "assujeitados", os seres da metamorfose morrem. Os modernos não reconhecem isso, como se não existisse nenhuma relação entre o "eu" e as entidades necessárias à sua fabricação (é essa a ação do DC).

\section{Seres da fiç̧ão}

Algo similar ocorre com os FIC. Eles, como os seres da metamorfose, precisam sair do ocultamento, já que, da mesma forma que a ciência criou um mundo material idealizado (uma “res-extensa-cogitans"), os modernos instauraram também um mundo simbólico (uma "rescogitans-cogitans"), instituindo o que Whitehead chama da grande bifurcação (WHITEHEAD, 1978). No fundo, mostra Latour no livro, o "mundo simbólico" nada mais é do que um artefato para dar consistência aos seres da ficção.

Os FIC têm seus próprios modos de verificação, de transcendência e de valor, como é o caso, por exemplo, dos objetos artísticos. O problema, mais uma vez, é matar as referências, não pagar o preço das mediações e traduções (RES) e sucumbir à tentação do DC, que os trata com condescendência, privando-os de realidade justamente por serem da "ficção", criaturas imaginárias do espírito humano. E mesmo os artistas vão aceitar e reivindicar serem artífices de um "mundo de ficção".

Para Latour, seria um erro de categoria tomá-los como "produtos da imaginação". A análise é muito interessante, pois os seres da ficção, bem como os da metamorfose, não vêm de um interior, de um mundo simbólico ou ficcional gerado pela nossa imaginação. 
Ao contrário, é a nossa imaginação, o nosso interior, a nossa subjetividade que nos é "oferecida" por eles, sem os quais não teríamos uma "subjetividade".

Os seres da ficção e da metamorfose nos preenchem (assim como os seres do jogo, com o seu espírito competidor, brincalhão, agonístico). Por exemplo, gostar de uma música, ou de jogar, não é "descarregar" do interior uma subjetividade (algo que seria da ordem da ficção e que vai de dentro para fora), mas o contrário. É ao ouvir música, ou jogar, que produzimos essa subjetividade, fazendo com que ela seja parte de uma trajetória de instauração que nos constituirá, justamente, como amantes da arte e do jogo. Só nessa condição esses seres sobrevivem. Eles precisam passar por nós para existir (se não apreciarmos, jogarmos, ou formos tomados por eles, eles morrem).

\section{Seres da técnica}

Erros de categoria provocam o ocultamento dos seres. O mesmo acontece, paradoxalmente, com os TEC. Estes desaparecem em meio a um gigantesco desenvolvimento tecnológico. Há uma profusão de artefatos e dispositivos técnicos desde o século XVII, mas pouca "filosofia" da técnica, pouco entendimento sobre os seus modos de existência. É preciso, portanto, descrever melhor esses seres e suas redes, sem cair em uma perspectiva essencialista, substancialista, ou de separação entre homem e objeto, típica da filosofia da técnica de Platão à Heidegger (LEMOS, 2014).

As redes sociotécnicas são formas de descrição da heterogeneidade dos dispositivos materiais de que dispomos em cada situação. As trajetórias dos seres da técnica nunca se desenvolvem de forma linear, "diretamente". Eles sempre se apresentam por desvios e apropriações, por invenções e transformações de matéria e energia. É justamente a falsa separação de sujeito e objeto nesta dinâmica da "presença-ausência" que leva os seres da técnica à ocultação. A visão instrumental e essencialista do fenômeno (a técnica é instrumento, o homem é o sujeito da técnica) de fato os escondem, permitindo a sua retirada do mundo e a instalação de um sistema independente.

Se a técnica está sempre velada, constituindo-se como um sistema total (ELLUL, 1968) de onde nada escapa, se ela é apenas produto da ciência e da economia, ela pode, efetivamente, retirar-se e agir como "sistema", como "perigo" e "destino" do 
homem no mundo (HEIDEGGER, 1958). Ela é assim um instrumento que realiza a separação do sujeito do objeto e de submissão da natureza, compreendida como um "reservatório" (a ideia do Gestell heideggeriano). Os modernos desenvolveram e ao mesmo tempo ocultaram a técnica ao produzirem um discurso essencialista.

No entanto, afirma Latour, considerar os seres da técnica como "meios para fins" é uma forma indigna de tratar seres tão importantes para a constituição do sujeito (entendido sempre como "quasi sujeito" articulado ao correlato "quasi objeto"). O importante, para dar ar de nobreza aos seres da técnica, é retirar do objeto técnico toda opacidade que o torna incompreensível e remontar a rede (que o DC quer apagar) à qual ele se liga por desvios e apropriações. O ser da técnica não pode ser identificado apenas como um objeto, uma coisa ou um dispositivo. Todo objeto é apenas a marca temporária de uma trajetória, de redes sociotécnicas sempre em movimento.

O modo justo de verificação de sua condição de felicidade não passa por essências imutáveis, como toda a ontologia da Enquête, mas por ajustes, retificações, apropriações, desvios, dobras e acoplamentos. Definitivamente, não é o objeto técnico que funciona em sua integralidade (enquanto indivíduo e substância), que demonstra o verdadeiro e o falso do seu modo de existência. Não é a sua essência velada, escondida das redes de um "ser enquanto ser" que pode revelar o modo de existência dos seres da técnica. Só o demônio DC aceita tomar a técnica na sua essência, apagando as redes e mediações.

Duas ações são fundamentais para entender o seu modo de existência: a dobra e o desengate ("pli" e "débrayage"). A dobra (pli) é uma forma de evitar falar de domínio técnico (independente) sobre a matéria, a natureza, a sociedade, a cultura, a economia, o sujeito. Há nesse "pli” aquilo que é, a cada associação, "implicado", "complicado", “explicado", joga Latour com as palavras. Logo, nada de linear ou de substantivo pode explicar os modos de existência dos seres da técnica. Já o desengate é o que acopla e desacopla, como uma caixa de marchas de um automóvel, é o que "faz fazer", o que mobiliza os planos de ação e causa as transformações no espaço, no tempo e nos tipos de atores (actantes mobilizando metamorfoses e reproduções). É pelo desengate e pela dobra que o homem é "projetado".

Como os seres da metamorfose e da ficção, os sujeitos emergem também pela mediação dos seres da técnica. Não se trata, consequentemente, do "Homo faber", senhor da técnica (entendida como ferramenta ou instrumento), do sujeito, que lida com o objeto oculto em sua essência (nunca revelada) e o inventa, transforma e dá sentido a ele. Pela 
Enquête, o homem é mais um "Homo fabricatus", inventado pelos acoplamentos e dobras da tecnicidade. Consequentemente, liberados da matéria, do domínio (pela dobra) e do sujeito (pelos engates e desengates), os seres da técnica podem se livrar da visão instrumental e essencialista para, enfim, saírem do ocultamento criado pelos modernos.

\section{Seres do jogo}

Não terei espaço aqui para apresentar toda a importância do lúdico na vida humana e para os modernos. Os trabalhos de Huizinga (2005) e Caillois (2001), para ficar em dois clássicos, mostram como o jogo é um elemento central da cultura. Mas, seguindo a lógica da Enquête, jogo aqui não é elemento de contexto. Situado como um modo de existência, damos a ele espaço para desenvolver sua trajetória para além do mundo humano. Os seres do jogo, portanto, nos interpelam e exigem nossa atenção para sobreviver, como os da ficção (FIC) e os da metamorfose (MET). Eles seguem sua trajetória por intermédio de artefatos e regras próprias (TEC). O modo de existência do lúdico (LUD) alia assim os modos anteriores (MET, TEC, FIC).

Primeiro, podemos falar da solicitude e do assujeitamento. Assim com os modos citados anteriormente, o LUD produz a nossa subjetividade. No entanto, os seres do jogo precisam de nossa solicitude, da nossa atenção para existir. Nada pior para eles do que pessoas sem humor, sem interesse pelos jogos, sem espírito de competição. Sem a nossa atenção ao que é próprio do jogo, da brincadeira, de um outro espaçotempo (como os seres da metamorfose e da ficção), os seres do jogo morreriam. Outras culturas entendem muito bem isso e elaboraram formas ricas de expressar e valorizar o encontro com esses seres.

Lembremos o princípio da Enquête: seres só existem por meio de outros, buscando estabilidade e persistência na busca pela subsistência. Portanto, os seres do jogo se parecem com os FIC e da MET, já que nos convocam e nos constituem. E eles têm algo dos seres da técnica (TEC), já que precisam de dobras, desengates, desvios e apropriações para atingir suas condições de felicidade. Embora nem todos os jogos mobilizem artefatos, todos possuem, dos TEC, o "saber fazer". Este se traduz por regras claras, constituindo artificialmente o espaço-tempo do jogo. Os TEC são elementos importantes de sua trajetória, pois o lúdico 
se expressa sempre por redes sociotécnicas. Passar por artefatos para criar um mundo à parte para brincar e jogar em um "círculo mágico" é a condição de felicidade do modo de existência do lúdico e dos seres do jogo.

No modo de existência do LUD, há algo que nos toca, seja pelo simples divertimento (a brincadeira), seja pela competição e a luta agonística em busca de um desafio a ser conquistado (o jogo). Há mesmo algo de "ludus" e de "paedia", portanto, nos seres do jogo. Eles produzem um mundo para além da querela entre narratologia e ludologia, convocando narrativas midiáticas (e hoje transmidiáticas), bem como aspectos competitivos agonísticos. O modo lúdico alcança sua condição de felicidade ao nos convocar (MET/FIC), e essa convocação se dá sempre por “intermédios” — técnicas, objetos, mídias (TEC).

Mas os seres do jogo podem, também, encontrar outros, já que são seres da ligação entre ("quasi”) sujeitos e (“quasi”) objetos (ou "attachement", "moralidade” e "organização", como os denomina Latour no quarto grupo apontado anteriormente). É evidente que nossa subjetividade se faz pelas associações que desenvolvemos através dos objetos que nos circundam, como os brinquedos e fetiches. Eles se encaixam bem nesse grupo, já que fazem a ligação entre os "quasi sujeitos e quasi objetos". Esses seres do jogo criam um elo interessante entre os FIC e os TEC.

Ha algo de mágico no jogo. Não é sem impacto, sabemos, que os meninos brincam de guerra, carros e máquinas, e meninas de cozinha, boneca e moda. As subjetividades são construídas nos jogos que ligam esses "quasi-sujeitos" aos "quasi-objetos". Não seria, portanto, equivocado dizer que os seres do jogo são seres de ligação, já que sabemos que o que nos faz brincar ou jogar é efetivamente o que dá liga, o que faz associar, o que faz sociedade ou, como afirma Huizinga (2005), o que produz cultura. O modo lúdico tem algo do modo do "attachement" que cria valor e que se mantém na "organização" e na "moralidade". Pelo lúdico, ficamos muito tempo juntos rindo, jogando ou disputando em um outro mundo, fora do espaço ou do tempo, em um temporário círculo mágico que é fundamental para dar sustentação às ligações mais "sérias" do dia a dia quando cessa o jogo.

Como em outros modos, há sempre misturas, e precisamos achar a boa maneira de falar dele. Muitas vezes brincamos e não somos compreendidos: "Não quis dizer isso, foi só uma brincadeira!" Muitas vezes é preciso explicar o que se quer dizer por brincadeira, ou seja, é necessário corrigir erros de categoria ou de preposição. Sabemos que o bom jogo é aquele jogado/brincado enquanto duram as regras e elas são cumpridas, é aquele 
em que todos sabem que estão brincando/jogando e que concordam (de comum acordo ou pela regra) em terminar, é o que cria, temporariamente, uma boa convivência no espaço e tempo construídos artificialmente.

No entanto, em muitos casos, confundimos jogo com política, jogo com economia, jogo com esporte (sim, o esporte moderno não tem necessariamente uma relação direta com o modo de existência do lúdico, mas deve persegui-lo), jogo com direito, jogo com a economia, jogo com a tecnologia e a ciência. Há misturas de modos no "jogo da política", nos games e nas novas tecnologias, que mais parecem "brinquedinho" de adultos, nas interfaces gráficas, nas conversações, na sociabilidade, no perde e ganha dos negócios e da bolsa, no jogo das palavras do direito, buscando condições de julgamento, no jogo sagrado das palavras religiosas, buscando a salvação e a transformação...

Os seres da ficção, da técnica e da metamorfose, como vimos, "fazem fazer" e misturam-se em domínios, os mais diversos. O mesmo acontece com os seres do jogo. A Enquête nos ensina a evitar tomar um modo por outro, confundi-los, errar na preposição, gerando análises "infelizes", incapazes de "falar bem" de um determinado modo. Temos que ter "jogo de cintura" para falar bem desses seres do jogo.

Hoje, em meio aos processos de "gameficação" contemporâneos, os seres do jogo parecem estar se reproduzindo em todos os campos da cultura. Os jogos de realidade alternativa são os que melhor misturam os modos de existência do lúdico com outros modos, dentro de um jogo, justamente por quebrar, como afirmam muitos especialistas, o círculo mágico, mesmo estando dentro dele, na minha opinião.

Nos jogos tradicionais, os limites são mais claros. Quando jogo xadrez, quando jogo futebol ou quando brinco com meu filho, o espaço-tempo está claramente suspenso. Sabemos que estamos brincando e jogando. Em todas essas atividades, está clara a constituição de outro espaço-tempo, do "círculo mágico do jogo", em uma posição que procura as condições de felicidade dentro do seu "modo de existência".

\section{Agradecimentos}

Devo a André Holanda e a Leonardo Pastor algumas ideias e sugestões. No entanto, o texto é de minha inteira responsabilidade. 


\section{Referências}

CAILLOIS, Roger. Man, Play and Games. Chicago: University of Illinois Press, 2001.

ELLUL, Jacques. A técnica e o desafio do século. Rio de Janeiro: Paz e Terra, 1968.

HARMAN, Graham. The quadruple object. Winchester: Zero Books, 2011.

HEIDEGGER, Martin. Essais et conférences. Paris: Gallimard, 1958.

HUIZINGA, Johan. Homo Ludens: o jogo como elemento da cultura. São Paulo: Perspectiva, 2005.

LATOUR, Bruno. Jamais fomos modernos: ensaio de antropologia simétrica. Rio de Janeiro: Editora 34, 1994.

. LATOUR, Bruno. Reassembling the social: an introduction to actor-network theory. Oxford: Oxford University Press, 2005.

. LATOUR, Bruno. Enquête sur les modes d'existence: une anthropologie des modernes. Paris: La Découverte, 2012.

LEMOS, André. A Comunicação das coisas: Teoria ator-rede e cibercultura. São Paulo: Annablume, 2013.

. LEMOS, André. A crítica da crítica essencialista da cibercultura. In: OLIVEIRA, Lídia; BALDI, Vania (Orgs.). A insustentável leveza da web: retóricas, dissonâncias e práticas na sociedade em rede. Salvador: Edufba, 2014, p. 41-76.

WHITEHEAD, Alfred. Process and Reality: an essay in cosmology. New York: Free Press, 1978. 